\title{
Genome-wide transcriptional profiling of the Bacillus subtilis cold-shock response
}

\author{
Tanja Kaan, Georg Homuth, Ulrike Mäder, Julia Bandow \\ and Thomas Schweder
}

Author for correspondence: Thomas Schweder. Tel: + 493834 864212. Fax: + 493834864238.
e-mail: schweder@uni-greifswald.de

Institut für Mikrobiologie, Ernst-Moritz-ArndtUniversität Greifswald, F.-L.-Jahn-Str. 15, D-17487 Greifswald, Germany

\begin{abstract}
The transcriptome of Bacillus subtilis was analysed at different time points (30, 60 and $90 \mathrm{~min}$ ) after a temperature downshift from 37 to $18{ }^{\circ} \mathrm{C}$ using DNA macroarrays. This approach allowed the identification of around 50 genes exhibiting an increased mRNA level and around $\mathbf{5 0}$ genes exhibiting a decreased mRNA level under cold-shock conditions. Many of the repressed genes encode enzymes involved in the biosynthesis of amino acids, nucleotides and coenzymes, indicating metabolic adaptation of the cells to the decreased growth rate at the lower temperature. The strongest cold-inducible gene encodes fatty acid desaturase, which forms unsaturated fatty acids from saturated phospholipid precursors, thereby increasing membrane fluidity. The cold-shock-induced increase of mRNA levels of the classical cold-shock genes $\operatorname{cspB}, \operatorname{cspC}$ and $\operatorname{cspD}$ could be verified. Furthermore, besides many genes encoding proteins of unknown function, some genes encoding ribosomal proteins were transcriptionally up-regulated, which points to an adaptive reprogramming of the ribosomes under cold-shock conditions. Interestingly, the amount of mRNA specified by the operon ptb-bcd-buk-Ipd-bkdA1-bkdA2$b k d B$, which encodes enzymes involved in degradation of branched-chain amino acids, also increases after a temperature downshift. As cells utilize the isoleucine and valine degradation intermediates $\alpha$-methylbutyryl-CoA and isobutyryl-CoA for synthesis of branched-chain fatty acids, this finding reflects the adaptation of membrane lipid composition, ensuring the maintenance of appropriate membrane fluidity at low temperatures. The results of the DNA array analyses were verified for several selected genes by RNA slot-blot analysis and compared with two-dimensional PAGE analyses.
\end{abstract}

Keywords: temperature downshift, transcriptome, proteome, mRNA, DNA array

\section{INTRODUCTION}

In its natural environment, the surface layer of soil, the Gram-positive mesophilic bacterium Bacillus subtilis is exposed to drastic temperature changes. Recently, the following problems of mesophilic bacteria under coldshock conditions have been addressed (Graumann \& Marahiel, 1999): (a) low membrane fluidity, (b) unwinding of the DNA double helix due to increased superhelical density of the DNA, (c) reduced enzyme activities, (d) decreased initiation of translation due to stabilized secondary structures of the mRNAs, (e) adaptation of the ribosomes and (f) slower protein folding. Thus, a temperature downshift requires a dramatic adaptive cellular response which has to be realized by global changes in the gene expression pattern.

Although synthesis of the majority of proteins decreases after a temperature downshift, the level of a specific group of proteins increases under these conditions in $B$. subtilis (Lottering \& Streips, 1995; Graumann et al., 1996). Using two-dimensional (2D) protein gel electrophoresis, it has been demonstrated that the synthesis of at least 37 proteins of $B$. subtilis increases after a temperature shift from 37 to $15^{\circ} \mathrm{C}$ (Graumann et al., 1996). It is supposed that these proteins play important roles in the adaptation of the cellular machinery to lowtemperature conditions (Graumann \& Marahiel, 1999). One of the highest accumulating protein groups of $B$. 
subtilis after a temperature downshift is formed by CspB, CspC and CspD (Graumann et al., 1996). It is assumed that these cold-shock proteins are able to bind mRNA and thus act as RNA chaperones, keeping critical mRNAs accessible for the ribosomes under low-temperature conditions (Graumann et al., 1997; Schindler et al., 1999). Furthermore, it has been suggested that coldshock-induced proteins associated with translation, e.g. the ribosomal proteins $S 6$ and L7/L12, are involved in the adaptation of ribosome function to low-temperature conditions (Graumann \& Marahiel, 1999). There are also indications that prolyl isomerization represents a problem that cells have to cope with at low temperatures (Kandror \& Goldberg, 1997; Graumann \& Marahiel, 1999). Increasing levels of the peptidyl-prolyl cis-trans isomerases PpiB and Tig of B. subtilis in response to cold shock have been described by Graumann et al. (1996). Finally, it has been observed that the level of several enzymes required for general cellular metabolism, e.g. amino acid synthesis or glycolysis, increases after a temperature downshift (Graumann \& Marahiel, 1999). It was suggested that the higher protein level compensates for the lower activity of these essential enzymes under low-temperature conditions.

It is supposed that the expression of most cold-shockinduced proteins is regulated mainly at the posttranscriptional and translational level. However, examples of regulation of cold-inducible genes at the transcriptional level have also been described. One example is the des gene of B. subtilis (Aguilar et al., 1998). This gene encodes a $\Delta 5$-lipid desaturase and exhibits one of the highest induction ratios during cold shock (Aguilar et al., 1999). The des mRNA level strongly increases $30 \mathrm{~min}$ after a temperature downshift. Recently, it has been described that expression of des is regulated by a two-component signal transduction system composed of the sensor kinase DesK and the response regulator DesR (Aguilar et al., 2001).

Besides direct transcriptional induction of cold-shock gene expression, mRNA stabilization after a temperature downshift has also been addressed as a mechanism for increased synthesis of cold-shock-induced proteins. It has been demonstrated that the overall mRNA halflife increases sixfold when B. subtilis cells are shifted from 37 to $20^{\circ} \mathrm{C}$ (Aguilar et al., 1999). For the genes of the major cold-shock proteins of B. subtilis, CspB and CspC, an approximately 40-fold increase in mRNA stability after a temperature downshift was shown (Kaan et al., 1999), which is significantly greater than the increase in bulk mRNA stability. A similar dramatic stabilization has been described for the mRNA of the major cold-shock protein of Escherichia coli, CspA (Brandi et al., 1996; Goldenberg et al., 1996; Fang et al., 1997). Thus, besides the translational regulation of the synthesis of cold-shock proteins, transcriptional and post-transcriptional events are of importance for the adaptational response of bacterial cells under coldshock conditions.

The aim of this study was to obtain a more comprehensive view of the cold-shock response of B. subtilis.
2D protein gel electrophoresis allows analysis of distinct groups of proteins from various cellular compartments with some limitations. However, global gene expression profiling by means of DNA arrays allows the transcriptional analysis of all genes of a specific genome at one defined time point. We analysed the transcriptome of $B$. subtilis after a temperature downshift from 37 to $18^{\circ} \mathrm{C}$. This approach allowed the identification of 46 genes exhibiting increased mRNA levels and 52 genes exhibiting decreased mRNA levels under cold-shock conditions. The contribution of altered mRNA levels to the varying amounts of proteins after cold shock was analysed by comparing transcriptome and proteome data.

\section{METHODS}

Bacterial strains and growth conditions. B. subtilis 168 $(\operatorname{trpC2})$ was used in this study (Anagnostopoulos \& Spizizen, 1961). This strain was cultivated under vigorous agitation at 37 and $18{ }^{\circ} \mathrm{C}$ in a synthetic minimal medium supplemented with glucose $(0 \cdot 2 \%)$ and tryptophan $\left(50 \mu \mathrm{g} \mathrm{ml}^{-1}\right)$ (Stülke et al., 1993). The cold shock was carried out as a temperature downshift from 37 to $18^{\circ} \mathrm{C}$ at an $\mathrm{OD}_{500}$ of about $0 \cdot 4$.

Growth experiments were performed with B. subtilis strains BFS4469, BFS4564, YHEAd, BFS4794 and BFS4226 carrying pMUTIN integrations (Vagner et al., 1998) in ydeB, ydjO, $y b e A, y q g A$ and $y a c K$, respectively. Strains were cultivated in the minimal medium described above as well as in Spizizen's minimal medium (Spizizen, 1958) supplemented with $0 \cdot 2 \%$ glucose and $0.08 \mathrm{mM}$ tryptophan. Erythromycin and lincomycin were added to final concentrations of 1 and $10 \mu \mathrm{g} \mathrm{ml}^{-1}$, respectively.

RNA extraction. For RNA extraction, B. subtilis cells were disrupted in liquid-nitrogen-chilled vessels using a Micro Dismembrator S (Braun Biotech International) for $2 \mathrm{~min}$ at 2600 r.p.m. Total RNA was isolated by using the single step method as described by Chomczynski \& Sacchi (1987). The RNA pellet was resuspended in sterile water and the RNA concentration was determined spectrophotometrically.

Preparation of labelled CDNA and hybridization to macroarrays. Reverse transcription and hybridization of the purified labelled target cDNA to $B$. subtilis nylon arrays were performed as described by Wiegert et al. (2001) with the following modifications: $10 \mu \mathrm{g}$ total RNA was used, and macroarrays and specific cDNA primers were purchased from Eurogentec. Hybridization signals were detected by exposure of the arrays to a storage phosphor screen (Molecular Dynamics). Each analysis was carried out twice using two independently isolated RNA preparations and two different array batches.

Data analysis. After scanning of the phosphor screens using a Storm 840 Phosphor Imager (Molecular Dynamics), the resulting images were analysed using ArrayVision 5.1 software (Imaging Research). Calculation of normalized intensity values of the individual spots was performed using the overallspot-normalization function of ArrayVision. To avoid extreme intensity ratios for genes close to or below the detection limit, signal intensity values corresponding to a signal to noise $(S / N)$ ratio $<1 \cdot 0$ were scaled up to a value corresponding to an $S / N$ ratio $=1 \cdot 0$. Further analyses were carried out using GeneSpring 3.2.12 software (Silicon Genetics). Genes exhibiting $S / N$ ratios $\geqslant 3$ under at least one growth condition 
Table 1. List of primers used for the generation of PCR products

\begin{tabular}{|c|c|c|}
\hline Gene & Primer & Sequence $5^{\prime} \rightarrow 3^{\prime *}$ \\
\hline \multirow[t]{2}{*}{ des } & T7DESFOR & CGTATCTTCAATGGCAGCAC \\
\hline & T7DESREV & CTAATACGACTCACTATAGGGAGACAAAGATCAGACAG \\
\hline \multirow[t]{2}{*}{$\operatorname{csp} B$} & T7CSPBFOR & $\overline{\text { CGGATTCATCGAAGTAGAAGG }}$ \\
\hline & T7CSPBREV & CTAATACGACTCACTATAGGGAGAACGTTAGCAGCTTGTGGTCCG \\
\hline \multirow[t]{2}{*}{$\operatorname{csp} C$} & T7CSPCFOR & $\overline{\text { CGAACGCGAAAATGGAGACG }}$ \\
\hline & T7CSPCREV & CTAATACGACTCACTATAGGGAGAACGTTAGCAGCTTGAG \\
\hline \multirow[t]{2}{*}{ purA } & T7PURAFOR & $\overline{\text { ATGTCTTCAGTAGTTGTAGTA }}$ \\
\hline & T7PURAREV & CTAATACGACTCACTATAGGGAGATTAGTTCGCACGGTACACACTG \\
\hline \multirow[t]{2}{*}{$y y d G$} & T7YYDGFOR & GAGAGTTAGTAACTG \\
\hline & T7YYDGREV & CTAATACGACTCACTATAGGGAGACCCAATTCCTCTAAA \\
\hline \multirow[t]{2}{*}{$y v c E$} & T7YVCEFOR & $\overline{\text { GACATTAACGATAAG }}$ \\
\hline & T7YVCEREV & CTAATACGACTCACTATAGGGAGAAGTTGTCGCCGTTTG \\
\hline \multirow[t]{2}{*}{$a p t$} & T7APTFOR & $\overline{\text { GGATTACCCGAAAGA }}$ \\
\hline & T7APTREV & CTAATACGACTCACTATAGGGAGACTGCCGTCAAGGTAA \\
\hline \multirow[t]{2}{*}{$y v f G$} & T7YVFGFOR & $\overline{\text { CCGTCCCTTATTTTA }}$ \\
\hline & T7YVFGREV & CTAATACGACTCACTATAGGGAGACTCCACGTTTGACTT \\
\hline \multirow[t]{2}{*}{$m n t A$} & T7MNTAFOR & TTGCGACCTTTGCTTTAACG \\
\hline & T7MNTAREV & CTAATACGACTCACTATAGGGAGATCTTTTGTGCCСTTTTCACC \\
\hline
\end{tabular}

* The T7 RNA polymerase recognition sequence of the reverse primers is underlined.

were considered to be significantly expressed. All genes specifying signals below this significance threshold were excluded from further data analysis. Then, the mean of the normalized intensity values of the duplicate spots of each gene was used to calculate the expression level ratios. Induction or repression ratios $\geqslant 2$ in both experiments were considered as significant.

Final evaluation of the macroarray data included the consideration of putative operons derived from the genome sequence using the SubtiList database (http://genolist. pasteur.fr/SubtiList/) as well as previously known transcriptional units. Genes exhibiting significant expression ratios were checked for their transcriptional organization. If these genes were members of polycistronic transcriptional units, further members of these operons were also included in the resulting tables even if their expression parameters did not fulfil the significance criteria.

RNA slot-blot analysis. Digoxigenin-labelled probes were obtained by in vitro transcription with T7 RNA polymerase using PCR-generated DNA fragments as templates. Primers used for PCR are listed in Table 1. Reverse primers contained the T7 RNA polymerase recognition sequence. The probes were generated with the Dig Chem Link Labelling and Detection Set (Roche Diagnostics).

Slot-blot analysis was performed with 0.5 or $10 \mu$ g total RNA by using standard methods (Wetzstein et al., 1992). For quantification of specific mRNAs, serial dilutions of total RNA in $10 \times$ SSC were transferred to a positively charged nylon membrane and hybridized with the appropriate genespecific probe.

Hybridization signals were detected according to the manufacturer's instructions (Roche Diagnostics). Chemiluminographs were analysed with a Lumi-Imager and the LumiAnalyse-software package (Boehringer Mannheim). Signals corresponding to mRNA samples taken from B. subtilis cells at $37^{\circ} \mathrm{C}$ served as standards and were set to 1 .

2D PAGE analyses. Pulse labelling of the bacterial culture for 5 min with $10 \mu \mathrm{Ci} \mathrm{L-}\left[{ }^{35} \mathrm{~S}\right]$ methionine $\mathrm{ml}^{-1}$ during exponential growth was carried out as described by Schmid et al. (1997). After sonication of the harvested cells, the amount of protein was determined by using Roti-Nanoquant (Roth). Crude protein extracts $(50 \mu \mathrm{g}$ protein) were loaded onto IPG strips for the first dimension of 2D gel electrophoresis (Völker et al., 1994). The second dimension was carried out as described by Bernhardt et al. (1997). After fixation and silver staining, the wet gels were scanned with a Hewlett Packard Scan Jet 6000 in transmission mode at a resolution of 300 d.p.i. and an 8 bit/256 greys colour depth. For autoradiography of the radiolabelled protein pattern (after separation of 2 million c.p.m.), the dried gels were exposed to storage phosphor screens (Molecular Dynamics Storage Phosphor Screen ; $20 \times 25 \mathrm{~cm}$ ) for $1-7 \mathrm{~h}$ and scanned with a STORM 840 Phosphor Imager (Molecular Dynamics) at a resolution of $200 \mu \mathrm{m}$ and a colour depth of 16 bit/65536 greys.

For computer-aided analysis of the gels, Delta2D 1.1 software (Decodon) was used as described by Bernhardt et al. (1999). The protein spots were relocated from the Sub2D database (Bernhardt \& Werner, 1999).

\section{RESULTS AND DISCUSSION}

\section{Transcriptome analysis: genes exhibiting significantly decreased mRNA levels}

For the transcriptome analysis of cold-shocked $B$. subtilis cells, samples were taken at 30, 60 and $90 \mathrm{~min}$ after a temperature downshift from 37 to $18^{\circ} \mathrm{C}$. The growth rate of the cells decreased after the cold shock from $0 \cdot 8 \mathrm{~h}^{-1}$ at $37^{\circ} \mathrm{C}$ to $0 \cdot 1 \mathrm{~h}^{-1}$ at $18{ }^{\circ} \mathrm{C}$. The DNA array approach revealed 52 genes organized in 
The table shows the calculated mRNA ratios for the individual genes averaged from two parallel experiments, the partially putative transcriptional organization and the functions of the encoded gene products, also partially putative. If the calculated ratios at one given time point fulfil the strongest significance criteria (signal values threefold above the cut-off value and ratios differing at least twofold from the wild-type), the ratios are given in bold type. The SD of the mRNA ratios is presented in parentheses. Based on the proteome analyses, a decrease in the level of the corresponding protein is indicated by $(-)$ and an increase is indicated by $(+)$.

\begin{tabular}{|c|c|c|c|c|c|}
\hline Gene & $\begin{array}{l}30 \text { min } \\
\text { cold shock }\end{array}$ & $\begin{array}{l}60 \text { min } \\
\text { cold shock }\end{array}$ & $\begin{array}{l}90 \text { min } \\
\text { cold shock }\end{array}$ & Transcriptional organization & Gene product function (partially putative) \\
\hline \multicolumn{6}{|l|}{$\begin{array}{l}\text { Cell-wall-associated } \\
\text { functions }\end{array}$} \\
\hline wapA & $2 \cdot 8(0 \cdot 4)$ & $\mathbf{5 . 9}(0 \cdot 9)$ & $3 \cdot 2(0 \cdot 7)$ & $w a p A-y x x G$ & Cell-wall-associated protein precursor \\
\hline$y x x G$ & $4 \cdot 8(0 \cdot 7)$ & $\mathbf{5} \cdot \mathbf{3}(1 \cdot 2)$ & $8 \cdot 3(1 \cdot 9)$ & wapA-yxxG & Unknown function \\
\hline$y w t D$ & $2 \cdot 1(0 \cdot 5)$ & $5 \cdot 6(0 \cdot 9)$ & $3 \cdot 5(0 \cdot 4)$ & $y w t D$ & Similar to murein hydrolase \\
\hline \multicolumn{6}{|l|}{$\begin{array}{l}\text { Transport/binding proteins } \\
\text { and lipoproteins }\end{array}$} \\
\hline ориСA & $1 \cdot 4(0 \cdot 4)$ & $4 \cdot 4(0 \cdot 9)$ & $4 \cdot 8(0 \cdot 8)$ & ориСС-ориСВ-ориСА-ориСD & $\begin{array}{l}\text { Glycine betaine/carnitine/choline } \mathrm{ABC} \\
\text { transporter (ATP-binding protein) }\end{array}$ \\
\hline ори CB & $1 \cdot 2(0 \cdot 4)$ & $4 \cdot 2(0 \cdot 8)$ & $4 \cdot 6(0 \cdot 9)$ & ориСС-ориСВ-ориСА-ориСD & $\begin{array}{l}\text { Glycine betaine/carnitine/choline } \mathrm{ABC} \\
\text { transporter (membrane protein) }\end{array}$ \\
\hline opuCC & $1 \cdot 5(0 \cdot 3)$ & $3.7(0 \cdot 9)$ & $4 \cdot 6(1 \cdot 2)$ & ориСС-ориСВ-ориСA-ориCD & $\begin{array}{l}\text { Glycine betaine/carnitine/choline } \mathrm{ABC} \\
\text { transporter (osmoprotectant-binding protein) }\end{array}$ \\
\hline ориCD & - & - & - & ориСС-ориСВ-ориСA-ориCD & $\begin{array}{l}\text { Glycine betaine/carnitine/choline } \mathrm{ABC} \\
\text { transporter (osmoprotectant-binding protein) }\end{array}$ \\
\hline yocs & $1 \cdot 8(0 \cdot 4)$ & $5 \cdot 3(1 \cdot 2)$ & $4 \cdot 0(1 \cdot 3)$ & yocs & Similar to sodium-dependent transporter \\
\hline yodF & $2 \cdot 0(0 \cdot 6)$ & $3.5(0 \cdot 7)$ & $2 \cdot 7(0 \cdot 9)$ & yodF & Similar to proline permease \\
\hline \multicolumn{6}{|l|}{ Amino acid biosynthesis } \\
\hline$i l v B$ & $1 \cdot 4(-)(0 \cdot 4)$ & $3 \cdot 9(-)(1 \cdot 4)$ & $0 \cdot 7(-)(0 \cdot 3)$ & ilvB-ilvN-ilvC-leuA-leuB-leuC-leuD & Acetolactate synthase (large subunit) \\
\hline$i l v N$ & $2 \cdot 0(0 \cdot 7)$ & $5.6(1 \cdot 9)$ & $4 \cdot 2(1 \cdot 7)$ & ilvB-ilvN-ilvC-leuA-leuB-leuC-leuD & Acetolactate synthase (small subunit) \\
\hline$i l v C$ & $1 \cdot 3(+)(0 \cdot 2)$ & $4 \cdot 4(+)(1 \cdot 2)$ & $2 \cdot 6(+)(1 \cdot 5)$ & ilvB-ilvN-ilvC-leuA-leuB-leuC-leuD & Ketol-acid reductoisomerase \\
\hline $\operatorname{leu} A$ & $2 \cdot 5(-)(0 \cdot 6)$ & $8 \cdot 3(-)(3 \cdot 1)$ & $4 \cdot 4(-)(2 \cdot 3)$ & ilvB-ilvN-ilvC-leuA-leuB-leuC-leuD & 2-Isopropylmalate synthase \\
\hline $\operatorname{leuB}$ & $1 \cdot 9(-)(0 \cdot 3)$ & $7 \cdot 7(-)(4 \cdot 1)$ & $4 \cdot 6(-)(1 \cdot 4)$ & ilvB-ilvN-ilvC-leuA-leuB-leuC-leuD & 3-Isopropylmalate dehydrogenase \\
\hline $\operatorname{leu} \mathrm{C}$ & $1 \cdot 7(-)(0 \cdot 5)$ & $\mathbf{5} \cdot \mathbf{0}(-)(2 \cdot 1)$ & $2 \cdot 2(-)(0 \cdot 9)$ & ilvB-ilvN-ilvC-leuA-leuB-leuC-leuD & 3-Isopropylmalate dehydratase (large subunit) \\
\hline $\operatorname{leuD}$ & $1 \cdot 4(0 \cdot 2)$ & $4 \cdot 3(1 \cdot 4)$ & $2 \cdot 6(0 \cdot 8)$ & ilvB-ilvN-ilvC-leuA-leuB-leuC-leuD & 3-Isopropylmalate dehydratase (small subunit) \\
\hline$i l v D$ & $2 \cdot 2(-)(0 \cdot 7)$ & $6 \cdot 7(-)(1 \cdot 5)$ & $2 \cdot 1(-)(0 \cdot 6)$ & $i l v D$ & Dihydroxyacid dehydratase \\
\hline met $C$ & $2 \cdot 9(1 \cdot 3)$ & $3.9(0.7)$ & $4 \cdot 0(0 \cdot 8)$ & met $C$ & Cobalamin-independent methionine synthase \\
\hline \multicolumn{4}{|l|}{ Metabolism of nucleotides } & guaB & Inosine monophosphate dehydrogenase \\
\hline purE & $2 \cdot 4(0 \cdot 4)$ & $1 \cdot 0(0 \cdot 2)$ & $2 \cdot 6(0 \cdot 7)$ & $\begin{array}{l}\text { purE-purK-purB-purC-yexA-purL-purQ- } \\
\text { purF-purM-purN-purH-purD }\end{array}$ & $\begin{array}{l}\text { Purine biosynthesis: } \\
\text { phosphoribosylaminoimidazole carboxylase I }\end{array}$ \\
\hline purK & $0 \cdot 9(0 \cdot 0)$ & $1 \cdot 8(0 \cdot 3)$ & $2 \cdot 1(0 \cdot 2)$ & $\begin{array}{l}\text { purE-purK-purB-purC-yexA-purL-purQ- } \\
\text { purF-purM-purN-purH-purD }\end{array}$ & $\begin{array}{l}\text { Purine biosynthesis: } \\
\text { phosphoribosylaminoimidazole carboxylase II }\end{array}$ \\
\hline
\end{tabular}


Table 2. (cont.)

\begin{tabular}{|c|c|c|c|c|c|}
\hline Gene & $\begin{array}{l}30 \text { min } \\
\text { cold shock }\end{array}$ & $\begin{array}{l}60 \text { min } \\
\text { cold shock }\end{array}$ & $\begin{array}{l}90 \text { min } \\
\text { cold shock }\end{array}$ & Transcriptional organization & Gene product function (partially putative) \\
\hline purB & $1 \cdot 6(0 \cdot 1)$ & $2 \cdot 6(0 \cdot 1)$ & $2 \cdot 6(0 \cdot 4)$ & $\begin{array}{l}\text { purE-purK-purB-purC-yexA-purL-purQ- } \\
\text { purF-purM-purN-purH-purD }\end{array}$ & Purine biosynthesis: adenylosuccinate lyase \\
\hline purC & $1 \cdot 3(0 \cdot 3)$ & $4 \cdot 2(0 \cdot 6)$ & $4 \cdot 8(0 \cdot 9)$ & $\begin{array}{l}\text { purE-purK-purB-purC-yexA-purL-purQ- } \\
\text { purF-purM-purN-purH-purD }\end{array}$ & $\begin{array}{l}\text { Purine biosynthesis: } \\
\text { phosphoribosylaminoimidazole } \\
\text { succinocarboxamide synthetase }\end{array}$ \\
\hline$y e x A$ & $5.9(2 \cdot 7)$ & $2 \cdot 5(0.6)$ & $4 \cdot 8(1 \cdot 4)$ & $\begin{array}{l}\text { purE-purK-purB-purC-yexA-purL-purQ- } \\
\text { purF-purM-purN-purH-purD }\end{array}$ & Unknown function \\
\hline purL & $1 \cdot 8(0 \cdot 4)$ & $5.0(1.4)$ & $2 \cdot 6(0 \cdot 5)$ & $\begin{array}{l}\text { purE-purK-purB-purC-yexA-purL-purQ- } \\
\text { purF-purM-purN-purH-purD }\end{array}$ & $\begin{array}{l}\text { Purine biosynthesis: } \\
\text { phosphoribosylformylglycinamidine synthetase II }\end{array}$ \\
\hline purQ & $1 \cdot 3(0 \cdot 2)$ & $5 \cdot 6(1 \cdot 2)$ & $0 \cdot 6(0 \cdot 4)$ & $\begin{array}{l}\text { purE-purK-purB-purC-yexA-purL-purQ- } \\
\text { purF-purM-purN-purH-purD }\end{array}$ & $\begin{array}{l}\text { Purine biosynthesis: } \\
\text { phosphoribosylformylglycinamidine synthetase I }\end{array}$ \\
\hline purF & $2 \cdot 0(-)(0 \cdot 2)$ & $3 \cdot 5(-)(0 \cdot 4)$ & $4 \cdot 6(-)(0 \cdot 5)$ & $\begin{array}{l}\text { purE-purK-purB-purC-yexA-purL-purQ- } \\
\text { purF-purM-purN-purH-purD }\end{array}$ & $\begin{array}{l}\text { Purine biosynthesis: glutamine } \\
\text { phosphoribosylpyrophosphate amidotransferase }\end{array}$ \\
\hline purM & $1 \cdot 6(0 \cdot 1)$ & $1 \cdot 6(0 \cdot 3)$ & $1 \cdot 8(0 \cdot 2)$ & $\begin{array}{l}\text { purE-purK-purB-purC-yexA-purL-purQ- } \\
\text { purF-purM-purN-purH-purD }\end{array}$ & $\begin{array}{l}\text { Purine biosynthesis: } \\
\text { phosphoribosylaminoimidazole synthetase }\end{array}$ \\
\hline $\operatorname{purN}$ & $1 \cdot 7(0 \cdot 2)$ & $8 \cdot 3(4 \cdot 1)$ & $5 \cdot 3(2 \cdot 7)$ & $\begin{array}{l}\text { purE-purK-purB-purC-yexA-purL-purQ- } \\
\text { purF-purM-purN-purH-purD }\end{array}$ & $\begin{array}{l}\text { Purine biosynthesis: phosphoribosylglycinamide } \\
\text { formyltransferase }\end{array}$ \\
\hline purH & $1 \cdot 4(0 \cdot 1)$ & $5.9(2 \cdot 2)$ & $\mathbf{5 \cdot 0}(1 \cdot 6)$ & $\begin{array}{l}\text { purE-purK-purB-purC-yexA-purL-purQ- } \\
\text { purF-purM-purN-purH-purD }\end{array}$ & $\begin{array}{l}\text { Purine biosynthesis: inosine monophosphate } \\
\text { cyclohydrolase }\end{array}$ \\
\hline purD & $1 \cdot 0(0 \cdot 1)$ & $1 \cdot 8(0 \cdot 3)$ & $3 \cdot 2(1 \cdot 3)$ & $\begin{array}{l}\text { purE-purK-purB-purC-yexA-purL-purQ- } \\
\text { purF-purM-purN-purH-purD }\end{array}$ & $\begin{array}{l}\text { Purine biosynthesis: phosphoribosylglycinamide } \\
\text { synthetase }\end{array}$ \\
\hline$y m a A$ & $1 \cdot 5(0 \cdot 1)$ & $2 \cdot 7(0 \cdot 3)$ & $2.9(0.5)$ & $y m a A-n r d E-n r d F-y m a B$ & Unknown function \\
\hline$n r d E$ & $2 \cdot 2(0 \cdot 2)$ & $4 \cdot 4(0 \cdot 3)$ & $4 \cdot 6(0 \cdot 9)$ & $y m a A-n r d E-n r d F-y m a B$ & $\begin{array}{l}\text { Ribonucleoside diphosphate reductase (major } \\
\text { subunit) }\end{array}$ \\
\hline$n r d F$ & - & - & - & $y m a A-n r d E-n r d F-y m a B$ & $\begin{array}{l}\text { Ribonucleoside diphosphate reductase (minor } \\
\text { subunit) }\end{array}$ \\
\hline$y m a B$ & - & - & - & $y m a A-n r d E-n r d F-y m a B$ & Unknown function \\
\hline $\begin{array}{l}\text { Metabolism of coenzymes } \\
\text { thiA }\end{array}$ & $1 \cdot 4(-)(0 \cdot 1)$ & $7 \cdot 7(-)(4 \cdot 2)$ & $\mathbf{5} \cdot \mathbf{3}(-)(2 \cdot 6)$ & thiA & $\begin{array}{l}\text { Biosynthesis of the pyrimidine moiety of thiamine } \\
\text { (thiamine biosynthesis) }\end{array}$ \\
\hline bioW & $1 \cdot 3(0 \cdot 1)$ & $4 \cdot 4(1 \cdot 4)$ & $2.5(0.5)$ & bioW-bioA-bioF-bioD-bioB-bioI & $\begin{array}{l}\text { Biotin biosynthesis: 6-carboxyhexanoate-CoA } \\
\text { ligase }\end{array}$ \\
\hline bioA & $1 \cdot 3(0 \cdot 2)$ & $4 \cdot 5(1.5)$ & $2 \cdot 6(0 \cdot 4)$ & bioW-bioA-bioF-bioD-bioB-bioI & $\begin{array}{l}\text { Biotin biosynthesis: adenosylmethionine-8-amino- } \\
\text { 7-oxononanoate aminotransferase }\end{array}$ \\
\hline bioF & $1 \cdot 2(0 \cdot 1)$ & $4 \cdot 4(1 \cdot 4)$ & $2 \cdot 8(0 \cdot 5)$ & bioW-bioA-bioF-bioD-bioB-bioI & $\begin{array}{l}\text { Biotin biosynthesis: } 8 \text {-amino-7-oxononanoate } \\
\text { synthase }\end{array}$ \\
\hline bioD & $1 \cdot 2(0 \cdot 1)$ & $4 \cdot 6(1 \cdot 5)$ & $3 \cdot 1(0 \cdot 6)$ & bioW-bioA-bioF-bioD-bioB-bioI & Biotin biosynthesis: dethiobiotin synthetase \\
\hline bioB & $1 \cdot 2(0 \cdot 1)$ & $4 \cdot 1(1 \cdot 3)$ & $2.9(0.6)$ & bioW-bioA-bioF-bioD-bioB-bioI & Biotin biosynthesis: biotin synthetase \\
\hline biol & $1 \cdot 2(0 \cdot 1)$ & $4 \cdot 0(1 \cdot 2)$ & $2.9(0 \cdot 7)$ & bioW-bioA-bioF-bioD-bioB-bioI & Biotin biosynthesis: cytochrome P450-like enzyme \\
\hline
\end{tabular}


Table 2. (cont.)

\begin{tabular}{|c|c|c|c|c|c|}
\hline Gene & $\begin{array}{l}30 \text { min } \\
\text { cold shock }\end{array}$ & $\begin{array}{l}60 \text { min } \\
\text { cold shock }\end{array}$ & $\begin{array}{l}90 \text { min } \\
\text { cold shock }\end{array}$ & Transcriptional organization & Gene product function (partially putative) \\
\hline \multicolumn{6}{|c|}{ Protein synthesis } \\
\hline$y k r T$ & $1 \cdot 4(-)(0 \cdot 1)$ & $4 \cdot 0(-)(1 \cdot 4)$ & $2 \cdot 7(-)(0 \cdot 6)$ & $y k r T-y k r S$ & Unknown function \\
\hline \multicolumn{6}{|c|}{ Detoxification } \\
\hline$a h p C$ & $1 \cdot 6(0 \cdot 1)$ & $4 \cdot 4(1 \cdot 6)$ & $4 \cdot 0(1 \cdot 4)$ & $a h p C-a h p F$ & Alkyl hydroperoxide reductase (small subunit) \\
\hline$a h p F$ & $1 \cdot 7(0 \cdot 2)$ & $4 \cdot 6(1 \cdot 7)$ & $3.9(1 \cdot 2)$ & $a h p C-a h p F$ & $\begin{array}{l}\text { Alkyl hydroperoxide reductase (large subunit) and } \\
\text { NADH dehydrogenase }\end{array}$ \\
\hline$y x b A$ & - & - & - & $y x b B-y x b A-y x n B-a s n H-y x a M$ & Unknown function \\
\hline$y \times n B$ & $1 \cdot 8(0 \cdot 2)$ & $6 \cdot 7(2 \cdot 7)$ & $\mathbf{9 \cdot 1}(5 \cdot 4)$ & $y x b B-y x b A-y x n B-a s n H-y x a M$ & Unknown function \\
\hline $\mathrm{asnH}$ & $1 \cdot 6(0 \cdot 2)$ & $5 \cdot 9(2 \cdot 1)$ & $5.9(2 \cdot 3)$ & $y x b B-y x b A-y x n B-a s n H-y x a M$ & Asparagine synthetase \\
\hline$y x a M$ & $1 \cdot 9(0 \cdot 3)$ & $7 \cdot 7(3 \cdot 9)$ & $6 \cdot 3(1 \cdot 6)$ & $y x b B-y x b A-y x n B-a s n H-y x a M$ & Similar to antibiotic resistance protein \\
\hline$y j b C(-)$ & $\mathbf{5 . 6}(-)(0 \cdot 4)$ & $2 \cdot 4(-)(0 \cdot 4)$ & $1 \cdot 9(-)(0 \cdot 4)$ & $y j b C$ & Unknown function \\
\hline
\end{tabular}


17 transcriptional units which exhibited significantly decreased mRNA levels (Table 2).

Most of the proteins encoded by the 52 down-regulated genes fulfil metabolic functions. The ilvBHCleuABCD operon (Grandoni et al., 1992) as well as the monocistronic ilvD gene encode enzymes involved in the biosynthesis of branched-chain amino acids. The metC gene, encoding cobalamin-independent methionine synthase, as well as the bicistronic $y k r T S$ operon, belong to the S-box regulon encompassing genes that are mainly involved in sulfate assimilation and methionine biosynthesis (Grundy \& Henkin, 1998). Whereas the $y k r T$ gene product most probably plays a role in the pathway that generates methionine from $5^{\prime}$-methylthioadenosine, a by-product of polyamine biosynthesis, the $y k r S$ gene product shows similarity to the eukaryotic translation initiation factor eIF-2B (Murphy et al., 2002). In all these cases, the maximal decrease in the mRNA levels was observed $60 \mathrm{~min}$ after the cold shock. The asnH gene encoding asparagine synthetase lies within the pentacistronic $y x b B-y x b A-y \times n B-a s n H-y x a M$ operon which exhibited the strongest decreased expression obtained in this study. Expression of the guaB gene encoding the inosine-monophosphate dehydrogenase involved in biosynthesis of GMP (Saxild \& Nygaard, 1988) was maximally decreased 60 min after the cold shock. On average, the large purEKBC-yexA-purLQFMNHD operon encoding purine biosynthesis enzymes (Ebbole $\&$ Zalkin, 1987) also showed a reduced transcript level under cold-shock conditions, although the mRNA level ratios of the single genes were more heterogeneous compared to the genes mentioned above. In the case of the tetracistronic $y m a A-n r d E-n r d F-y m a B$ operon, which encodes the major and the minor subunit of ribonucleoside-diphosphate reductase (Scotti et al., 1996) and exhibited a continuous decreasing mRNA level after cold shock, the signal values obtained for the two distal genes of the operon were below the significance threshold, therefore allowing no reliable quantification. Finally, the bioWAFDBI operon, encoding the biotin biosynthetic enzymes (Bower et al., 1996), and the monocistronic thiC gene, whose product is involved in the biosynthesis of the pyrimidine moiety of thiamine (Begley et al., 1999), showed the strongest decrease in their mRNA levels 60 min after cold shock.

Besides genes encoding proteins involved in amino acid biosynthesis, nucleotide and coenzyme metabolism, other down-regulated genes can be functionally classified in different groups. The mRNA levels of the opuCACBCCCD operon strongly decreased $60 \mathrm{~min}$ after the temperature downshift. This operon encodes a glycine betaine/carnitine/choline $\mathrm{ABC}$ transporter involved in osmoprotection (Kappes et al., 1999). The monocistronic yocS and yodF genes most probably also encode transport/binding proteins, in particular a sodium-dependent transporter and a proline permease, respectively. Both genes revealed maximally decreased mRNA levels 60 min after the temperature downshift.

Two down-regulated transcriptional units specify proteins fulfilling cell-wall-associated functions: the bicistronic wapA-yxxG operon and the monocistronic $y w t D$ gene. Whereas wapA encodes a cell-wall-associated protein precursor (Foster, 1993), the function of the co-transcribed $y \times x G$ gene is unknown. Due to its sequence similarity, the gene product of $y w t D$ most probably represents a murein hydrolase.

The bicistronic $a h p C-a h p F$ operon, encoding the small and large subunits of the alkyl hydroperoxide reductase, was also strongly down-regulated by $60 \mathrm{~min}$ after cold shock. This enzyme fulfils an essential function in detoxification under conditions of oxidative stress (Antelmann et al., 1996). The transcript level of the $y j b C$ gene encoding a general stress protein of unknown function (Petersohn et al., 2001) exhibited the maximal decrease by 30 min after cold shock.

The physiological function of the down-regulated genes is partially evident. In the case of $y w t D$, which most probably encodes a murein hydrolase, the reduction of the mRNA level could ensure the adjustment of the enzyme amount to the reduced growth rate under coldshock conditions. Murein hydrolases are essentially involved in cell growth and cell division. Similarly, reduced expression of wapA, encoding a cell-wallassociated protein precursor (Foster, 1993), could function to adapt the amount of this large membrane protein to the general decline in membrane- and cell-walllocated functions during growth in the cold. The downregulation of the $a h p C-a h p F$ operon could reflect the lower activity of the respiratory chain enzymic components at low temperatures, resulting in a reduced production of potentially toxic, highly reactive side products of respiratory chain reactions.

The reduced expression of the following transcriptional units specifying biosynthetic enzymes can also be interpreted as consequence of the lower growth rate after cold shock: bioWAFDBI, thiA, ymaA-nrdEF$y$ maB, purEKBC-yexA-purLQFMNHD, guaB, metC, $i l v D$ and ilvBHCleuABCD. All encoded enzymes from these genes are involved in major biosynthetic processes, such as the biosynthesis of amino acids, nucleotides and coenzymes. Therefore, it is obvious to speculate that the observed decreased mRNA levels reflect the cellular reaction to the reduced growth rate at lower temperature.

The physiological relevance of the down-regulation of the glycine betaine $\mathrm{ABC}$ transporter opuCACBCCCD as well as of yocS and yodF, encoding transporter/ permease proteins, remains unclear. The $o p u C$ operon functions in coping with osmotic stress (Kappes et al., 1999). The operon encodes an ABC transporter responsible for the uptake of the compatible solutes glycine betaine, carnitine and choline. It is transcriptionally induced under conditions of increased osmolarity, but also expressed at a low level under conditions of moderate osmolarity. The adaptive effect of a lowering of the basal expression of the opuC operon under cold-shock conditions is not obvious. 
The table shows the calculated mRNA ratios for the individual genes averaged from two parallel experiments, the partially putative transcriptional organization and the functions of the encoded gene products, also partially putative. If the calculated ratios at one given time point fulfil the strongest significance criteria (signal values threefold above the cut-off value and ratios differing at least twofold from the wild-type), the ratios are given in bold type. The SD of the mRNA ratios is presented in parentheses. Based on the proteome analyses, a decrease of the level of the corresponding protein is indicated by $(-)$ and an increase is indicated by $(+)$.

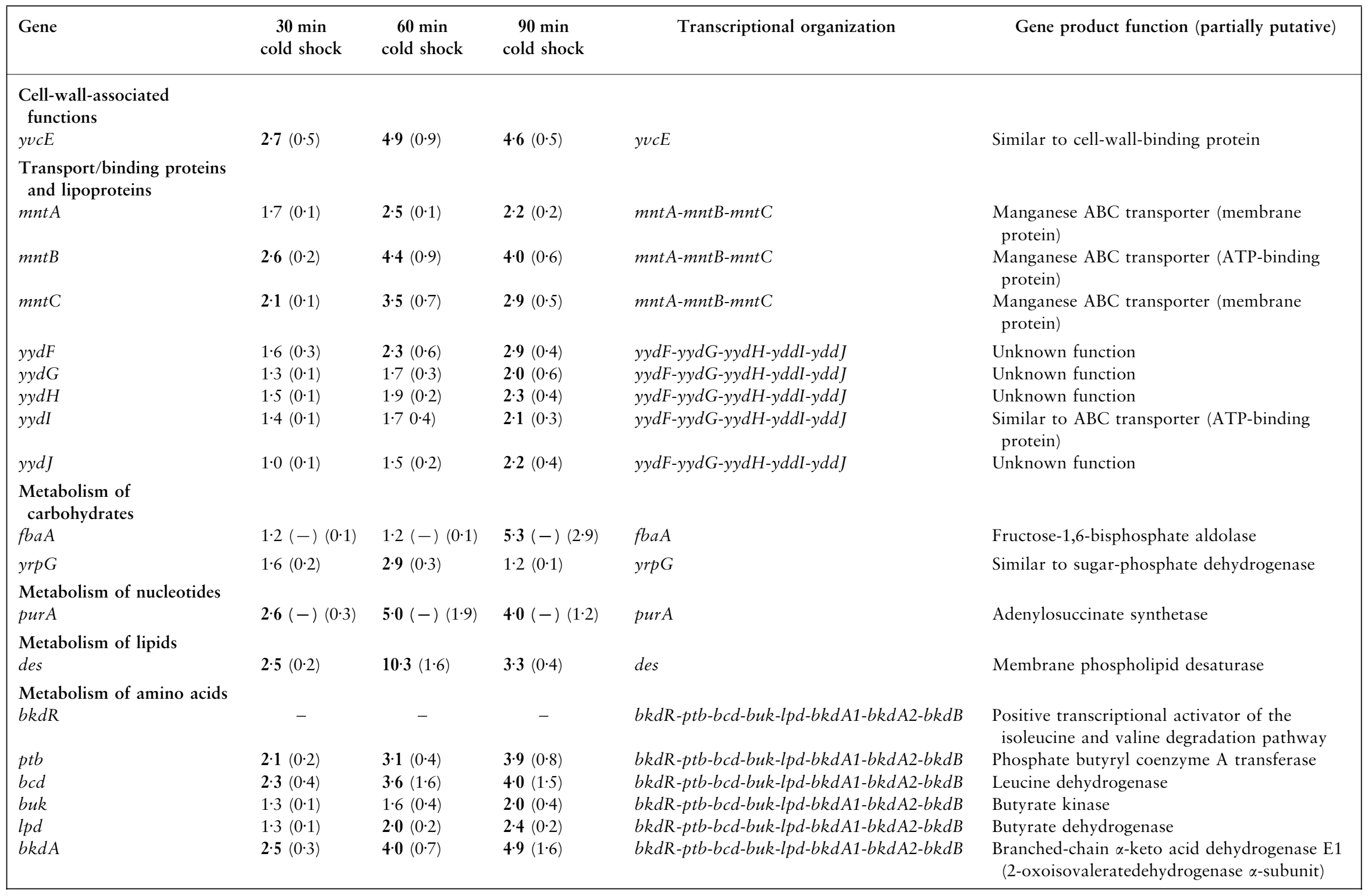


Table 3. (cont.)

\begin{tabular}{|c|c|c|c|c|c|}
\hline Gene & $\begin{array}{l}30 \text { min } \\
\text { cold shock }\end{array}$ & $\begin{array}{l}60 \text { min } \\
\text { cold shock }\end{array}$ & $\begin{array}{l}90 \text { min } \\
\text { cold shock }\end{array}$ & Transcriptional organization & Gene product function (partially putative) \\
\hline$b k d A 2$ & $1 \cdot 7(0 \cdot 2)$ & $2 \cdot 6(0 \cdot 3)$ & $3 \cdot 4(0 \cdot 2)$ & $b k d R-p t b-b c d-b u k-l p d-b k d A 1-b k d A 2-b k d B$ & $\begin{array}{l}\text { Branched-chain } \alpha \text {-keto acid dehydrogenase E1 } \\
\text { (2-oxoisovalerate dehydrogenase } \beta \text {-subunit) }\end{array}$ \\
\hline$b k d B$ & $2.9(0 \cdot 4)$ & $4 \cdot 8(1 \cdot 7)$ & $5 \cdot 2(2 \cdot 9)$ & $b k d R-p t b-b c d-b u k-l p d-b k d A 1-b k d A 2-b k d B$ & $\begin{array}{l}\text { Branched-chain } \alpha \text {-keto acid dehydrogenase E2 } \\
\text { subunit (lipoamide acyltransferase) }\end{array}$ \\
\hline $\begin{array}{l}\text { RNA synthesis - elongation } \\
\text { rpoE }\end{array}$ & $1 \cdot 6(0 \cdot 1)$ & $2 \cdot 2(0 \cdot 2)$ & $2 \cdot 3(0 \cdot 1)$ & rpoE & RNA polymerase $(\delta$-subunit $)$ \\
\hline $\begin{array}{l}\text { RNA modification } \\
y u g I\end{array}$ & $1 \cdot 4(+)(0 \cdot 1)$ & $2 \cdot 8(+)(0 \cdot 4)$ & $3 \cdot 3(+)(0 \cdot 5)$ & $y u g I$ & $\begin{array}{l}\text { Similar to polyribonucleotide } \\
\text { nucleotidyltransferase }\end{array}$ \\
\hline \multicolumn{6}{|l|}{$\begin{array}{l}\text { Protein synthesis - ribosomal } \\
\text { proteins }\end{array}$} \\
\hline rplu & $1 \cdot 2(0 \cdot 2)$ & $1 \cdot 4(0 \cdot 1)$ & $1 \cdot 7(0 \cdot 3)$ & $r p l U-y s x B-r p m A$ & Ribosomal protein L21 (BL20) \\
\hline$y s x B$ & $1 \cdot 2(0 \cdot 1)$ & $1 \cdot 4(0 \cdot 1)$ & $1 \cdot 4(0 \cdot 1)$ & $r p l U-y s x B-r p m A$ & Similar to hypothetical proteins \\
\hline rpmA & $1 \cdot 3(0 \cdot 1)$ & $2 \cdot 4(0 \cdot 3)$ & $2 \cdot 1(0 \cdot 2)$ & $r p l U-y s x B-r p m A$ & Ribosomal protein L27 (BL24) \\
\hline$r p m E$ & $1 \cdot 0(0 \cdot 4)$ & $2 \cdot 1 \quad 0 \cdot 2)$ & $1.9(0 \cdot 2)$ & $r p m E$ & Ribosomal protein L31 \\
\hline $\mathrm{rpsO}$ & $1 \cdot 20 \cdot 2)$ & $2 \cdot 4(0 \cdot 3)$ & $2 \cdot 5(0 \cdot 3)$ & $r p s O$ & Ribosomal protein S15 (BS18) \\
\hline$y l b N$ & $1 \cdot 1(0 \cdot 1)$ & $2 \cdot 2(0 \cdot 2)$ & $3 \cdot 1(0 \cdot 2)$ & $y l b N-r p m F$ & Unknown function \\
\hline$r p m F$ & $0 \cdot 8(0 \cdot 2)$ & $2 \cdot 30 \cdot 2)$ & $4 \cdot 4(0 \cdot 8)$ & $y l b N-r p m F$ & Ribosomal protein L32 \\
\hline \multicolumn{6}{|l|}{$\begin{array}{l}\text { Adaptation to atypical } \\
\text { conditions }\end{array}$} \\
\hline $\operatorname{csp} B$ & $2 \cdot 6(+)(0 \cdot 3)$ & $4 \cdot 6(+)(1 \cdot 7)$ & $1 \cdot 9(+)(0 \cdot 1)$ & $\operatorname{csp} B$ & Major cold-shock protein \\
\hline $\operatorname{csp} C$ & $1 \cdot 4(0 \cdot 1)$ & $2 \cdot 1(0 \cdot 3)$ & $1 \cdot 1(0 \cdot 2)$ & $\operatorname{csp} C$ & Cold-shock protein \\
\hline $\operatorname{csp} D$ & $1 \cdot 0(+)(0 \cdot 1)$ & $1 \cdot 4(+)(0 \cdot 2)$ & $2 \cdot 9(+)(0 \cdot 4)$ & $\operatorname{cspD}$ & Cold-shock protein \\
\hline $\begin{array}{l}\text { Unknown function } \\
\text { ydeB }\end{array}$ & $1 \cdot 1(0 \cdot 1)$ & $4.9(2 \cdot 6)$ & $7 \cdot 5(2 \cdot 8)$ & $y d e B$ & Similar to proteins of unknown function \\
\hline$y d j O$ & $2 \cdot 6(0 \cdot 2)$ & $4.9(1.6)$ & $8 \cdot 1(3 \cdot 4)$ & $y d j O$ & Unknown function \\
\hline$y$ heA & $1 \cdot 4(0 \cdot 1)$ & $2 \cdot 3(0 \cdot 3)$ & $3 \cdot 3(1 \cdot 2)$ & $y h e A$ & Unknown function \\
\hline$y l b F$ & - & - & - & $y l b F-y l b G$ & Similar to hypothetical proteins \\
\hline$y l b G$ & $1 \cdot 6(0 \cdot 2)$ & $2 \cdot 1(0 \cdot 2)$ & $3 \cdot 0(0 \cdot 4)$ & $y l b F-y l b G$ & Similar to unknown proteins \\
\hline yneE & - & - & - & yneE-yneF & Unknown function \\
\hline yneF & $1 \cdot 5(0 \cdot 1)$ & $3 \cdot 2(0 \cdot 7)$ & $3 \cdot 1(1 \cdot 1)$ & yneE-yneF & Unknown function \\
\hline yom $T$ & $1 \cdot 0(0 \cdot 1)$ & $2 \cdot 7(1 \cdot 4)$ & $2 \cdot 2(0 \cdot 1)$ & yom $T$ & Unknown function \\
\hline yopU & $1 \cdot 5(0 \cdot 1)$ & $2 \cdot 4(0 \cdot 2)$ & $2 \cdot 3(0 \cdot 1)$ & yopU & Unknown function \\
\hline yorD & $1 \cdot 3(0 \cdot 1)$ & $3 \cdot 9(1 \cdot 1)$ & $2.9(0.5)$ & yorD & Unknown function \\
\hline$y p a A$ & $1 \cdot 5(0 \cdot 2)$ & $3 \cdot 3(0 \cdot 9)$ & $0 \cdot 9(0 \cdot 1)$ & $y p a A$ & Unknown function \\
\hline$y q f W$ & $2 \cdot 1(0 \cdot 1)$ & $2 \cdot 9(0 \cdot 3)$ & $2 \cdot 4(0 \cdot 1)$ & $y q f W$ & Unknown function \\
\hline$y q g A$ & $2 \cdot 4(0 \cdot 1)$ & $2 \cdot 2(0 \cdot 1)$ & $4 \cdot 0(0 \cdot 7)$ & $y q g A$ & Unknown function \\
\hline
\end{tabular}




\section{Transcriptome analysis: genes exhibiting significantly increased mRNA levels}

Approximately 46 genes exhibited significantly increased mRNA levels after the temperature downshift (Table 3). According to the time profile of the mRNA levels, these genes could be assigned to groups of earlyand late-induced genes. Most of the induced genes exhibited significantly elevated mRNA levels 60 or 90 min after the temperature downshift. However, a small group of genes revealed significantly increased mRNA levels by $30 \mathrm{~min}$.

The gene encoding the major cold-shock protein CspB belongs to the early cold-shock genes. This protein is assumed to play a crucial role in the adaptational response of $B$. subtilis to low-temperature conditions (Graumann et al., 1997). Further early-induced genes included members of the $p t b-b c d-b u k-l p d-b k d A 1-$ $b k d A 2-b k d B$ operon, encoding enzymes involved in the degradation of branched-chain amino acids (Debarbouille et al., 1999), the monocistronic des gene, encoding fatty acid desaturase, which forms unsaturated fatty acids from saturated phospholipid precursors (Aguilar et al., 1998), the mntA-mntB-mntC operon, encoding a manganese ABC transporter (Que \& Helmann, 2000), $y v c E$, encoding a protein similar to cell-wall-binding proteins, the monocistronic $y d j \mathrm{O}$, $y q g A$ and $y q f W$ genes, encoding proteins of unknown function, and the monocistronic purA gene, which encodes the adenylosuccinate synthetase involved in AMP biosynthesis (Mantsala \& Zalkin, 1992). Interestingly, all of these early-induced genes kept their increased mRNA levels over a time period of at least 90 min after the cold shock. The mRNA levels of $y q g A$, $y v c E, y d j O$ and the $p t b-b c d-b u k-l p d-b k d A 1-b k d A 2-$ $b k d B$ operon revealed a significant further increase within this time. The des gene exhibited a 10-fold increase in mRNA level 60 min after the cold shock and thus represents the highest induction ratio of all coldresponsive $B$. subtilis genes identified in this study. After $90 \mathrm{~min}$, a clear decrease of the amount of des mRNA was detected, indicating the transient character of des up-regulation during cold shock.

The majority of the cold-shock-induced genes was characterized by significantly increased mRNA levels after 60 or $90 \mathrm{~min}$. Two of these genes encode proteins with metabolic functions: the $f b a A$ gene, encoding fructose-1,6-bisphosphate aldolase (Tobisch et al., 1999), and the $y r p G$ gene, encoding a protein similar to sugar-phosphate dehydrogenase. Among the late-induced cold-shock genes, several exhibited only around twofold increased mRNA levels after 60 as well as 90 $\min$ : $r p o E$, encoding the $\delta$-subunit of RNA polymerase, $c s p C$ and $c s p D$, encoding cold-shock proteins, and $y o p U$, encoding a protein of unknown function. The operon $y y d F G H I J$, specifying a protein with similarity to an ATP-binding protein of an ABC transporter and four genes encoding products of unknown function, followed the same expression pattern. The late-induced monocistronic genes listed below exhibited a continuous increase in their mRNA levels up to 90 min after cold shock: $y u g I$, encoding a protein similar to polyribonucleotide nucleotidyltransferase, and $y h e A$ and $y d e B$, encoding proteins of unknown function. The monocistronic genes yom $T$, yorD and ypaA exhibited a transient increased mRNA pattern with a maximum after $60 \mathrm{~min}$. The late-induced $y l b G$ and $y n e F$ genes most probably represent members of the bicistronic operons $y l b F-y l b G$ and $y n e E-y n e F$, respectively. However, the promoter-proximal genes of these putative operons, $y l b F$ and $y n e E$, specified signals below the significance threshold. Therefore, it remains unclear if $y l b G$ and $y n e F$ are monocistronically transcribed from promoters immediately upstream of these genes.

Besides the known cold-shock genes $c s p B, c s p C$ and $\operatorname{csp} D$, there are further candidates, which possibly play roles in the adaptational response of $B$. subtilis cells to low-temperature conditions. In addition to the genes mentioned so far, one group of cold-inducible genes could function in the adaptation of the protein synthesis machinery. After the temperature downshift, we found increased $\mathrm{mRNA}$ levels of the following genes encoding ribosomal proteins : $r p m A$ (encoding L27), $r p m E$ (L31), $r p s \mathrm{O}$ (S15) and $r p m F$ (L32). The rpmF gene forms a bicistronic operon together with the promoter-proximal $y l b N$ gene, which encodes a protein with unknown function. Both genes exhibited elevated mRNA levels 60 min after the cold shock and a further increase in their mRNA levels after $90 \mathrm{~min}$. The genes $r p m E$ and $r p s \mathrm{O}$ are also co-transcribed as a bicistronic operon. There was a doubling in their mRNA levels 60 min after the temperature downshift and this was still the case after $90 \mathrm{~min}$. Finally, according to the genome sequence, $r p m A$ represents the promoter-distal gene of a tricistronic operon $r p l U-y s x B-r p m A$. There was a doubling in the rpmA-specific mRNA level after 60 and $90 \mathrm{~min}$, whereas the amount of the $r p l U-y s x B$ transcript was not significantly altered. Possibly, cold-dependent regulation of $r p m A$ is mediated by an internal promoter upstream of the gene.

The cold-shock-induced genes identified in this study for which putative functions have been addressed can be affiliated to two main groups. The genes belonging to the first group encode proteins with functions in the adaptation of the cells to low-temperature conditions. The second group encompasses genes encoding proteins required for normal vegetative cellular activities.

The genes $c s p B, c s p C$ and $c s p D$ belong to the first group of cold-shock-induced genes. For $\operatorname{csp} B$, the increase in the mRNA level was verified by slot-blot experiments (see below). Furthermore, the up-regulation of $c s p B$ and cspD mRNA levels was also reflected by a strong increase in the amount of the corresponding proteins as revealed by proteome analysis (see below). CspB and its homologous proteins carry conserved motifs that are essential for binding to single-stranded DNA and RNA (Schröder et al., 1995; Lopez et al., 1999, 2001). For CspB and related proteins, an RNA chaperone function has been proposed, facilitating translation at low 
temperature by blocking the formation of secondary structures in the mRNA (Graumann \& Marahiel, 1999). Recently, Weber et al. (2001b) demonstrated that CspB of B. subtilis is localized to zones of newly synthesized RNA, most probably coupling transcription with initiation of translation.

The strongest cold-shock-induced gene according to the array analysis was des, encoding a desaturase, which forms unsaturated fatty acids from saturated phospholipid precursors, thereby increasing membrane fluidity (Aguilar et al., 1999; Weber et al., 2001a). Membrane fluidity is one of the most important demands for cells during growth at low temperatures to maintain substrate transport via the cell envelope. The strong cold-inducibility of des was also verified by slotblot experiments (see below).

The genes encoding the ribosomal proteins L27, L31, L32 and S15 exhibited increased mRNA levels under cold-shock conditions. It is tempting to speculate that these proteins play a role in the low-temperature adaptation of the B. subtilis translational machinery, as suggested for the ribosomal proteins S6 and L7/L12 by Graumann et al. (1996).

The second group of cold-shock-induced genes is very diverse. This group includes genes fulfilling functions in the metabolism of carbohydrates $(f b a A, y r p G)$, nucleotides (purA), transport processes (mntABC, yydFGHIJ), RNA synthesis $(r p o E)$ and RNA modification (yugI). The mntABC operon encodes an ABC transporter for manganese uptake (Que \& Helmann, 2000). Transcription of this operon is controlled by the positive transcriptional regulator MntR which is activated in the absence of manganese ions. Possibly, manganese complexes with other ions like phosphates at low temperature and is thus limited. This could in turn activate MntR and consequently induce $m n t A B C$ expression. In this respect it is noteworthy that no increased mnt $A B C$ mRNA levels could be observed after a temperature downshift in Luria Broth (LB) complex medium (data not shown).

In the case of $f b a A$, encoding fructose-1,6-bisphosphate aldolase, there was a significant increase in the mRNA amount after $90 \mathrm{~min}$ cold shock. Interestingly, the proteome approach revealed a significant decrease in the FbaA protein level 30, 60 and 90 min after the temperature downshift. A possible explanation could be that the $f b a A$-specific mRNA is translationally blocked under cold-shock conditions, causing a reduction in the amount of the encoded protein. The late increase in the RNA level would then indicate the cellular reaction to equalize the lack in fructose-1,6-bisphosphate aldolase. A similar mechanism might be responsible for the increase in purA mRNA. This gene encodes the adenylosuccinate synthetase involved in purine biosynthesis and belongs to the genes with the highest increased mRNA levels under the conditions tested in this study. On the other hand, as in the case of $f b a A$, the proteome approach revealed a decreased level of the corresponding PurA protein after 30, 60 and 90 min cold shock.
The cold-shock-dependent regulation of the heptacistronic operon $p t b-b c d-b u k-l p d-b k d A 1-b k d A 2-b k d B$ is of special interest. The enzymes encoded by this operon catalyse the degradation of the branched-chain amino acids isoleucine and valine to branched-chain carboxylic acids (Debarbouille et al., 1999). Transcription of this operon has been shown to be strongly dependent on the alternate sigma factor SigL and positively regulated by the regulator BkdR. Furthermore, there is also a negative regulation via the transcriptional repressor CodY. The degradation intermediates of isoleucine and valine, $\alpha$-methylbutyryl-CoA and isobutyryl-CoA, are utilized for synthesis of anteisobranched fatty acids. These fatty acids, as components of membrane lipids, contribute essentially to sufficient fluidity of the membrane under low-temperature conditions. At low temperature, the content of anteisobranched fatty acids in B. subtilis increases and the level of iso-branched fatty acid species decreases (Klein et al., 1999). Besides the activity of the fatty acid desaturase, this system also contributes to the reorganization of the cell membrane at low temperature. However, the mechanism mediating the increase of the mRNA level of the $p t b-b c d-b u k-l p d-b k d A 1-b k d A 2-b k d B$ operon under cold-shock conditions remains unclear.

The increased mRNA levels identified by the transcriptome analyses in this study could be due to either an indirect post-transcriptional effect, such as the strong stabilization of the $\operatorname{cspB}$ or $c s p C$ mRNAs (Kaan et al., 1999) or a direct positive regulation at the transcriptional level. Recently, a two-component signal transduction system has been determined, which positively regulates the expression of the des gene, encoding the desaturase of B. subtilis under low-temperature conditions (Aguilar et al., 2001). These authors suggested that the DesK/DesR two-component system functions like a cold-shock thermometer. It could be demonstrated by footprinting experiments that the response regulator DesR binds to a specific region upstream of the des promoter. To verify whether additional cold-shockinduced genes could be regulated by this two-component system, we performed a sequence pattern search with the suggested binding region of DesR. However, none of the cold-shock-induced genes identified in this study was preceded by a similar sequence motif.

\section{Verification of DNA macroarray results by RNA slot- blot analysis}

To check the significance of the DNA array data, follow-up experiments were carried out. First, the RNA levels of selected cold-inducible genes derived from the transcriptome study were analysed by slot-blot experiments (Fig. 1). Altogether seven genes, all exhibiting significantly increased mRNA levels under cold-shock conditions, were chosen: $m n t A$, purA, yydG, yvcE, des, $c s p B$ and $c s p C$. The mRNA level of the first gene of the $m n t A B C$ operon, $m n t A$, was maximally increased 2.5fold in the array experiment after $60 \mathrm{~min}$. The slot-blot analysis revealed a corresponding maximal induction factor of 3.5 after $60 \mathrm{~min}$. The purA gene, showing a 


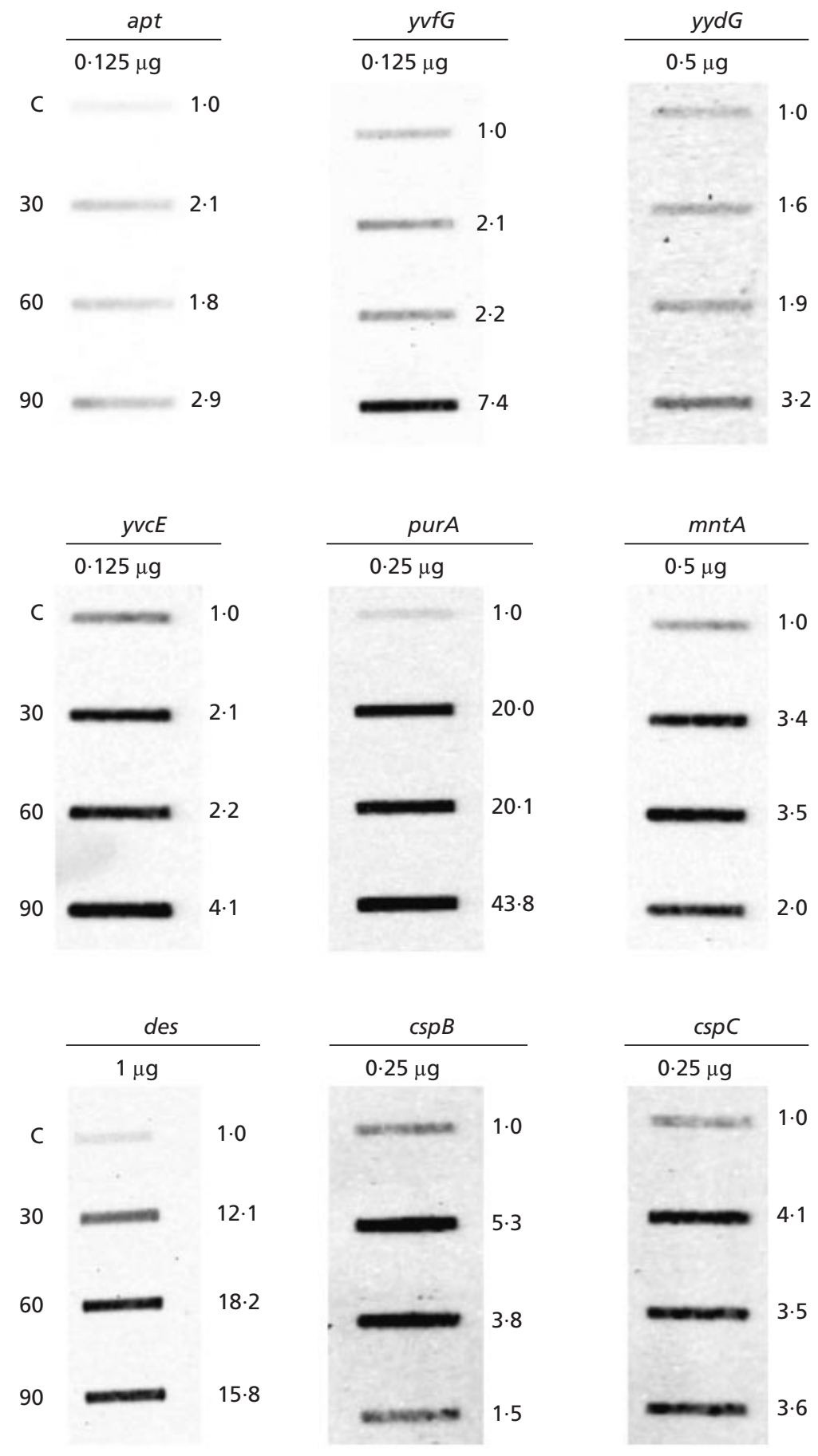


after $90 \mathrm{~min}$. This transient induction pattern was also reflected in the slot-blot experiments, although the absolute values for the induction ratios were higher: $12 \cdot 1,18 \cdot 2$ and $15 \cdot 8$, respectively. A transient increase in the mRNA level was also verified in the case of the $\operatorname{csp} B$ gene encoding the major cold-shock protein CspB. The array analysis resulted in mRNA ratios of 2.6 (30 min), $4 \cdot 6(60 \mathrm{~min})$ and $1.9(90 \mathrm{~min})$, corresponding to ratios of $5.3,3.8$ and 1.5 in the slot-blot experiment. In the case of the $c s p C$ mRNA, the macroarray analysis indicated a transient increase after $60 \mathrm{~min}$. The slot-blot experiments revealed an increase by $30 \mathrm{~min}$, followed by similar high mRNA levels after 60 and $90 \mathrm{~min}$.

In general, the results of the global transcriptome approach and the detailed analysis are comparable. Genes with significantly increased mRNA levels in the transcriptome study also showed increased mRNA levels in the slot-blot approach. In most cases, even the extent of the induction was similar. Therefore, the transcriptome data were broadly confirmed by the slotblot experiments.

\section{Comparison of DNA macroarray results with proteome data}

The DNA array results were checked further by a corresponding proteome analysis using a 2D PAGE technique. Comparison of $\left[{ }^{35} \mathrm{~S}\right]$ methionine-labelled cytoplasmic protein fractions prepared from cells cultivated at $37^{\circ} \mathrm{C}$ and at different times after the temperature downshift demonstrated that the protein synthesis capacity of the cold-shocked cells is drastically decreased. The incorporation rate of $\left.{ }^{35} \mathrm{~S}\right]$ methionine was reduced by a factor of five after the temperature downshift from 37 to $18^{\circ} \mathrm{C}$. Interestingly, the transcriptome approach resulted in the identification of only 52 genes exhibiting decreased mRNA levels, whereas the proteome approach revealed the down-regulation of the synthesis of significantly more proteins : about $30 \%$ of the protein spots visible in the control gel were not detectable in the $2 \mathrm{D}$ protein gels of the cold-shocked cells. This discrepancy verifies the earlier idea that the strong global down-regulation of gene expression under cold-shock conditions results primarily from inhibition of translation due to stabilized secondary structures of the mRNA. Among the proteins whose synthesis was strongly reduced after cold shock were IlvB, LeuA, LeuB, LeuC and IlvD, all identified as down-regulated by the transcriptomics approach, as shown in Table 2 . The decreased mRNA levels of guaB, purF, thiA, ykrT, $y k r S$ and $y j b C$ were also reflected at the protein level (Table 2). In all cases, apart from IlvC, the downregulated genes also showed a decreased expression at the protein level, if detectable on the $2 \mathrm{D}$ gels. In the macroarray analysis, all genes of the ilvBHCleuABCD operon revealed decreased mRNA levels, but the gene product of $i l v C$ increased at the protein level.

About 43 proteins demonstrating increased levels after the temperature downshift were identified by means of the 2D PAGE approach. The most dominant protein spots after the temperature downshift were represented by the cold-shock proteins CspB and CspD. The increased amount of these cold-shock proteins was observed $30 \mathrm{~min}$ after the temperature downshift. In the case of CspB, this expression pattern corresponds to the transcriptome analysis (Table 3), whereas in the case of CspD, an increased mRNA level was only detectable after $90 \mathrm{~min}$. Furthermore, the increased mRNA level of the $y u g I$ gene, encoding a putative polyribonucleotide nucleotidyltransferase, was also verified by the proteomics approach. In contrast, the proteins PurA and FbaA were present in lower amounts under cold-shock conditions, although their mRNA levels were increased.

Besides the cold-shock proteins CspB and CspD, the ribosomal proteins S6 and L7/L12 belonged to the most highly accumulating proteins under cold-shock conditions in B. subtilis. The number of cold-shockincreased proteins is pretty consistent with results from Graumann et al. (1996) who identified 37 cold-shock proteins by the 2D PAGE approach. However, there are slight differences between these two studies. We did not find significantly increased protein levels of the prolylisomerases PpiB and Tig, the cysteine synthase CysK or the glyceraldehyde phosphate dehydrogenase Gap under the conditions examined in this study. Although there are slight differences in the experimental design of Graumann et al. (1996) in comparison to our study, the reasons for these differences are not clear.

A considerable part of the proteins encoded by genes showing significantly increased mRNA levels in the DNA array experiments was not visible in the 2D PAGE analyses. In most cases, this was due to either an unfavourable alkaline $\mathrm{pH}$ or a low protein level.

Whereas the mRNA levels of most of the cold-shockinduced genes reached their maximum $60 \mathrm{~min}$ after the temperature downshift, the level of the majority of the cold-shock proteins was highest after $90 \mathrm{~min}$. This is consistent with the data of Graumann et al. (1996) who demonstrated that the cold-shock response in B. subtilis indeed represents a transient regulated phenomenon.

\section{Growth experiments of strains carrying null mutations in cold-shock-induced genes}

The mutant strains BFS4469, BFS4564, YHEAd and BFS4794 carry pMUTIN integrations in the genes $y d e B$, $y d j O$, yhe $A$ and $y q g A$, which were identified as strongly cold-shock-induced in the transcriptome analysis. These mutants were analysed for a cold-shock-sensitive growth phenotype.

Strains were inoculated with an exponentially growing preculture to an initial $\mathrm{OD}_{500}$ of 0.04 and cultivated at $37^{\circ} \mathrm{C}$ until reaching an $\mathrm{OD}_{500}$ of $0 \cdot 3$. Cultures were then shifted to $15^{\circ} \mathrm{C}$ by transferring them to a precooled shaker incubator and incubated for $30 \mathrm{~h}$. Two different minimal media were used (see Methods). The experiments were carried out several times and generated highly reproducible results. All mutants revealed a weak but significant growth disadvantage in comparison to 
the wild-type strain B. subtilis 168 . These decreased growth rates were most probably due to the necessity to cultivate the mutant strains in the presence of erythromycin and lincomycin to stabilize the single-crossover integration of the pMUTIN. Therefore, BFS4226, carrying a pMUTIN integration in yacK was used as an additional control. This strain was chosen because its expression was not changed by the cold shock. The yacK mutant showed the same growth behaviour as the other mutant strains (data not shown). Consequently, it has to be concluded that, at least under the conditions tested in this study, inactivation of the cold-inducible genes $y d e B$, $y d j O, y h e A$ and $y q g A$ does not significantly impair the fitness of $B$. subtilis at low temperature.

\section{ACKNOWLEDGEMENTS}

We are indebted to Michael Hecker, in whose laboratories this work was carried out, for critical reading of the manuscript, and Ken-Ichi Yoshida and Kazuo Kobayashi for providing strains. We thank Karin Binder for technical support. This work was supported by the Deutsche Bundesstiftung Umwelt and the Bundesministerium für Bildung und Forschung.

\section{REFERENCES}

Aguilar, P. S., Cronan, J. E., Jr \& De Mendoza, D. (1998). A Bacillus subtilis gene induced by cold shock encodes a membrane phospholipid desaturase. J Bacteriol 180, 2194-2200.

Aguilar, P. S., Lopez, P. \& De Mendoza, D. (1999). Transcriptional control of the low-temperature-inducible des gene, encoding the delta5 desaturase of Bacillus subtilis. J Bacteriol 181, 7028-7033.

Aguilar, P. S., Hernandez-Arriaga, A. M., Cybulski, L. E., Erazo, A. C. \& De Mendoza, D. (2001). Molecular basis of thermosensing: a two-component signal transduction thermometer in Bacillus subtilis. EMBO J 20, 1681-1691.

Anagnostopoulos, C. \& Spizizen, J. (1961). Requirements for transformation in Bacillus subtilis. J Bacteriol 81, 741-746.

Antelmann, H., Engelmann, S., Schmid, R. \& Hecker, M. (1996). General and oxidative stress responses in Bacillus subtilis: cloning, expression and mutation of the alkyl hydroperoxide reductase operon. J Bacteriol 178, 6571-6578.

Begley, T. P., Downs, D. M., Ealick, S. E. \& 8 other authors (1999). Thiamin biosynthesis in prokaryotes. Arch Microbiol 71, 293-300.

Bernhardt, J. \& Werner, H. (1999). The 2D protein index of Bacillus subtilis - Sub2D. http://microbio2.biologie.unigreifswald.de:8880/ (Ernst-Moritz-Arndt-Universität Greifswald, Greifswald, Germany).

Bernhardt, J., Völker, U., Völker, A., Antelmann, H., Schmid, R., Mach, H. \& Hecker, M. (1997). Specific and general stress proteins in Bacillus subtilis - a two dimensional protein electrophoresis study. Microbiology 143, 999-1017.

Bernhardt, J., Büttner, K., Scharf, C. \& Hecker, M. (1999). Dual channel imaging of two-dimensional electropherograms in $\mathrm{Ba}$ cillus subtilis. Electrophoresis 20, 2225-2240.

Bower, S., Perkins, J. B., Yocum, R. R., Howitt, C. L., Rahaim, P. \& Pero, J. (1996). Cloning, sequencing, and characterization of the Bacillus subtilis biotin biosynthetic operon. J Bacteriol 178, 4122-4130.

Brandi, A., Pietroni, P., Gualerzi, C. O. \& Pon, C. L. (1996). Posttranscriptional regulation of CspA expression in Escherichia coli. Mol Microbiol 19, 231-240.
Chomczynski, P. \& Sacchi, N. (1987). Single-step method of RNA isolation by acid guanidinium thiocyanate-phenol-chloroform extraction. Anal Biochem 162, 156-159.

Debarbouille, M., Gardan, R., Arnaud, M. \& Rapoport, G. (1999). Role of $b k d R$, a transcriptional activator of the SigL-dependent isoleucine and valine degradation pathway in Bacillus subtilis. J Bacteriol 181, 2059-2066.

Ebbole, D. J. \& Zalkin, H. (1987). Cloning and characterization of a 12-gene cluster from Bacillus subtilis encoding nine enzymes for de novo purine nucleotide synthesis. J Biol Chem 262, 8274-8287.

Fang, L., Jiang, W., Bae, W. \& Inouye, M. (1997). Promoterindependent cold shock induction of $\operatorname{csp} A$ and its derepression at $37^{\circ} \mathrm{C}$ by mRNA stabilisation. Mol Microbiol 23, 355-364.

Foster, S. J. (1993). Molecular analysis of three major wallassociated proteins of Bacillus subtilis 168: evidence for processing of the product of a gene encoding a $258 \mathrm{kDa}$ precursor two-domain ligand-binding protein. Mol Microbiol 8, 299-310.

Goldenberg, D., Azar, I. \& Oppenheim, A. B. (1996). Differential mRNA stability of the $\operatorname{csp} A$ gene in the cold-shock response of Escherichia coli. Mol Microbiol 19, 241-248.

Grandoni, J. A., Zahler, S. A. \& Calvo, J. M. (1992). Transcriptional regulation of the ilv-leu operon of Bacillus subtilis. J Bacteriol 174, 3212-3219.

Graumann, P., Schröder, K., Schmid, R. \& Marahiel, M. A. (1996). Cold shock stress-induced proteins in Bacillus subtilis. J Bacteriol 178, 4611-4619.

Graumann, P., Wendrich, T. M., Weber, M. H., Schröder, K. \& Marahiel, M. A. (1997). A family of cold shock proteins in Bacillus subtilis is essential for cellular growth and for efficient protein synthesis at optimal and low temperatures. Mol Microbiol 25, 741-756.

Graumann, P. L. \& Marahiel, M. A. (1999). Cold shock response in Bacillus subtilis. J Mol Microbiol Biotechnol 1, 203-209.

Grundy, F. J. \& Henkin, T. M. (1998). The $S$ box regulon: a new global transcription termination control system for methionine and cysteine biosynthesis genes in gram-positive bacteria. Mol Microbiol 30, 737-749.

Kaan, T., Jürgen, B. \& Schweder, T. (1999). Regulation of the expression of the cold shock proteins CspB and CspC in Bacillus subtilis. Mol Gen Genet 262, 351-354.

Kandror, O. \& Goldberg, A. L. (1997). Trigger factor is induced upon cold shock and enhances viability of Escherichia coli at low temperatures. Proc Natl Acad Sci US A 94, 4978-4981.

Kappes, R. M., Kempf, B., Kneip, S., Boch, J., Gade, J., MeierWagner, J. \& Bremer, E. (1999). Two evolutionarily closely related ABC transporters mediate the uptake of choline for synthesis of the osmoprotectant glycine betaine in Bacillus subtilis. Mol Microbiol 32, 203-216.

Klein, W., Weber, M. H. \& Marahiel, M. A. (1999). Cold shock response of Bacillus subtilis: isoleucine-dependent switch in the fatty acid branching pattern for membrane adaptation to low temperatures. J Bacteriol 181, 5341-5349.

Lopez, M. M., Yutani, K. \& Makhatadze, G. I. (1999). Interactions of the major cold shock protein of Bacillus subtilis CspB with single-stranded DNA templates of different base composition. J Biol Chem 274, 33601-33608.

Lopez, M. M., Yutani, K. \& Makhatadze, G. I. (2001). Interactions of the cold shock protein CspB from Bacillus subtilis with singlestranded DNA. Importance of the $\mathrm{T}$ base content and position within the template. J Biol Chem 276, 15511-15518.

Lottering, E. A. \& Streips, U. N. (1995). Induction of cold shock proteins in Bacillus subtilis. Curr Microbiol 30, 193-199. 
Mantsala, P. \& Zalkin, H. (1992). Cloning and sequence of Bacillus subtilis purA and guaA, involved in the conversion of IMP to AMP and GMP. J Bacteriol 174, 1883-1890.

Murphy, B. A., Grundy, F. J. \& Henkin, T. M. (2002). Prediction of gene function in methylthioadenosine recycling from regulatory signals. J Bacteriol 184, 2314-2318.

Petersohn, A., Brigulla, M., Haas, S., Hoheisel, J. D., Volker, U. \& Hecker, M. (2001). Global analysis of the general stress response of Bacillus subtilis. J Bacteriol 183, 5617-5631.

Que, Q. \& Helmann, J. D. (2000). Manganese homeostasis in Bacillus subtilis is regulated by $\mathrm{MntR}$, a bifunctional regulator related to the diphtheria toxin repressor family of proteins. Mol Microbiol 35, 1454-1468.

Saxild, H. H. \& Nygaard, P. (1988). Gene-enzyme relationships of the purine biosynthetic pathway in Bacillus subtilis. Mol Gen Genet 211, 160-167.

Schindler, T., Graumann, P. L., Perl, D., Ma, S., Schmid, F. X. \& Marahiel, M. A. (1999). The family of cold shock proteins of Bacillus subtilis. Stability and dynamics in vitro and in vivo. J Biol Chem 274, 3407-3413.

Schmid, R., Bernhardt, J., Antelmann, H., Völker, A., Mach, H., Völker, U. \& Hecker, M. (1997). Identification of vegetative proteins for two dimensional protein index of Bacillus subtilis. Microbiology 143, 991-998.

Schröder, K., Graumann, P., Schnuchel, A., Holak, T. A. \& Marahiel, M. A. (1995). Mutational analysis of the putative nucleic acid-binding surface of the cold-shock domain, CspB, revealed an essential role of aromatic and basic residues in binding of singlestranded DNA containing the Y-box motif. Mol Microbiol 16, 699-708.

Scotti, C., Valbuzzi, A., Perego, M., Galizzi, A. \& Albertini, A. M. (1996). The Bacillus subtilis genes for ribonucleotide reductase are similar to the genes for the second class I NrdE/NrdF enzymes of Enterobacteriaceae. Microbiology 142, 2995-3004.
Spizizen, J. (1958). Transformation of biochemically deficient strains of Bacillus subtilis by deoxyribonucleate. Proc Natl Acad Sci U S A 44, 1072-1084.

Stülke, J., Hanschke, R. \& Hecker, M. (1993). Temporal activation of the $\beta$-glucanase synthesis in Bacillus subtilis is mediated by the GTP pool. J Gen Microbiol 139, 2041-2045.

Tobisch, S., Zühlke, D., Bernhardt, J., Stülke, J. \& Hecker, M. (1999). Role of CcpA in regulation of the central pathways of carbon catabolism in Bacillus subtilis. J Bacteriol 181, 6996-7004.

Vagner, V., Dervyn, E. \& Ehrlich, S. D. (1998). A vector for systematic gene inactivation in Bacillus subtilis. Microbiology 144, 3097-3104.

Völker, U., Engelmann, S., Maul, B., Riethdorf, S., Völker, A., Schmid, R., Mach, H. \& Hecker, M. (1994). Analysis of the induction of general stress proteins of Bacillus subtilis. Microbiology 140, 741-752.

Weber, M. H., Klein, W., Müller, L., Niess, U. M. \& Marahiel, M. A. (2001a). Role of the Bacillus subtilis fatty acid desaturase in membrane adaptation during cold shock. Mol Microbiol 39, 1321-1329.

Weber, M. H., Volkov, A. V., Fricke, I., Marahiel, M. A. \& Graumann, P. L. (2001b). Localization of cold shock proteins to cytosolic spaces surrounding nucleoids in Bacillus subtilis depends on active transcription. J Bacteriol 183, 6435-6443.

Wetzstein, M., Völker, U., Dedio, J., Löbau, S., Zuber, U., Schiesswohl, M., Herget, C., Hecker, M. \& Schumann, W. (1992). Cloning, sequencing and molecular analysis of the dnaK locus from Bacillus subtilis. J Bacteriol 174, 3300-3310.

Wiegert, T., Homuth, G., Versteeg, S. \& Schumann, W. (2001). Alkaline shock induces the Bacillus subtilis sigmaW regulon. Mol Microbiol 41, 59-71.

Received 15 February 2002; revised 1 July 2002; accepted 23 July 2002. 